\title{
Mathematical descriptions of heat-mass- exchange processes in construction industry at control automation
}

\author{
Vladimir Velichkin", Vladimir Zavyalov, Elena Solodovnikova and Elena Filippova \\ Moscow State University of Civil Engineering, Yaroslavskoe shosse, 26, Moscow, 129337, Russia
}

\begin{abstract}
The paper covers matters arising in building mathematical model of processes at thermal treatment of construction materials. On the basis of analysis of heat energy and moisture flows in intermittent steam chamber and continuous tunnel drying chamber, analytic and structure models of heat-mass-exchange processes in processing vessels are drawn. The structural model of heat-mass-exchange processes allowed to evaluate the relationship of heat energy and moisture flows at heat treatment processes for gypsum and reinforced-concrete articles. The resulting system of interrelated differential equations is based on a structural model. Analytical studies showed that the considering heat treatment units are characterized by non-stationary, non-linear, stochastic and distributed technological parameters. An experimental study of technological devices has shown that in a limited time range, the processes of heat-massexchange can be characterized by a system of linear differential equations with constant coefficients with sufficient accuracy for practice. Acceptable allowances and simplifying assumptions at analytical description of heatmass-exchange processes in processing vessels are considered. As a result of performed research, various mathematical forms (differential equation system, matrix and operator forms) of mathematical models of processing vessels are obtained. The built mathematical models may be applied for constructing the processing vessels with preset dynamic properties, as well for control-system designing by those vessels.
\end{abstract}

\section{Introduction}

As is well known [1], units for construction material thermal treatment are multidimensional non-stationary control objects with distributed stochastic parameters which are characterised by nonlinearities.

Complete analytical description of processes in heat-mass-exchange units by classical methods is not realistic. In particular cases, when it works out, the solution turns to be extremely complicated, formidable and actually inapplicable for engineering practice. In relation therewith, a matter of approximate analytical solutions for problems of mathematical description of processes in heat-mass-exchange units occurs [2].

Studies of national and foreign specialists in the area of automatic control theory [3,4] demonstrated that mathematical model of control object must reflect its most substantial

\footnotetext{
* Corresponding author: velichkinva@mgsu.ru
} 
sides with such degrees of abstraction and detalisation, which are necessary and sufficient for achieving the purpose of model building.

\section{Research methods}

Herein, the purpose of modelling the thermal treatment process is in development of control strategy by formulated criterion of energy efficiency [5]. In relation with the above said, it is expedient to consider the thermal treatment unit as a heat-mass-exchange object in which energy and material interactions of the elements composing the unit are the most substantial processes.

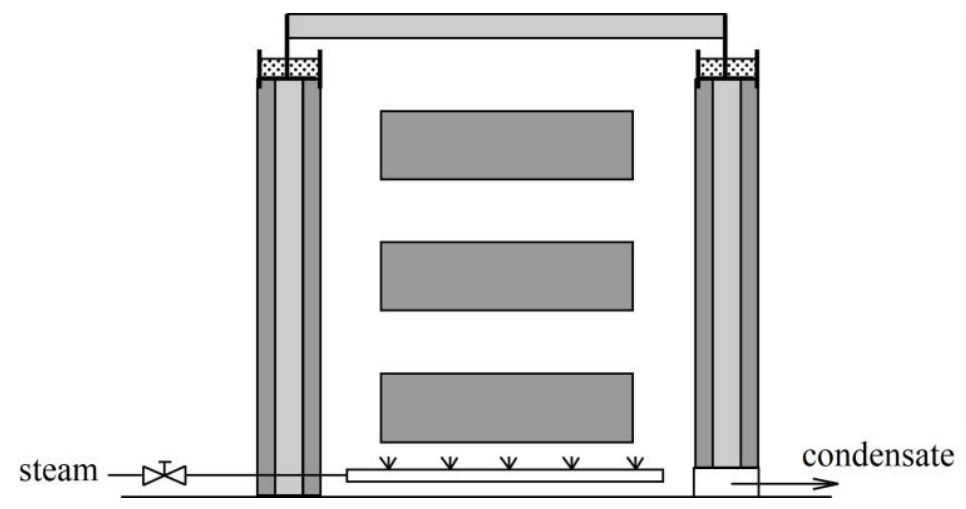

Fig. 1. Intermittent steam chamber

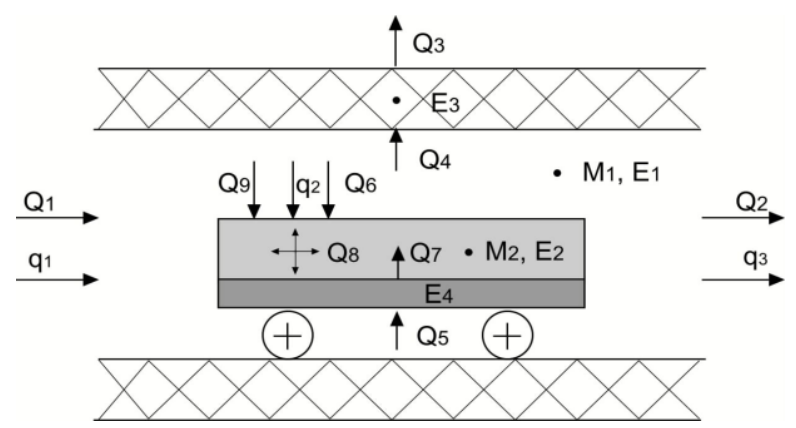

Fig. 2. Element of drying chamber

It is expedient to divide the unit into elements, subject to physical phenomena $[3,6]$, which characterise processes of heat-mass-exchange, and to the accepted optimality criterion. Studying of technical materials demonstrated that the main physical values which characterise heat treatment, may be considered the temperature and moisture capacity of main elements included into the thermal treatment unit.

The constructions possessing substantial capacities of heat or moisture are related to main elements. These are the material of the item to be processed, vehicle, environment of operating area of the unit as well as fencing.

On the basis of the set out statements, an analytic model of control objects may be drawn (Fig. 1 and 2) [4]. In drawing up the analytic model, the following assumptions were made in this paper:

- the part of the heat-treatment unit being considered, represents a lumped-parameter object;

- materials of the vehicle and fencing are not involved into mass exchange; 
- on a certain control interval the item remains immovable.

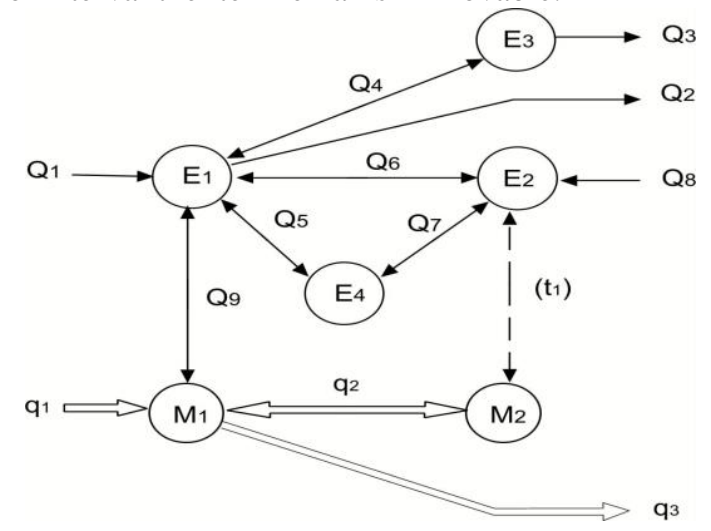

Fig. 3. Structure of heat and material flows in steam and drying chambers

In analytic model (Fig. 3) of the units being considered in this paper, the following flows of heat energy and moisture are taken into account: $Q_{1}$ - heat energy flow ingressing into the unit; $\mathrm{Q}_{2}$ - heat energy flow going out of the unit; $\mathrm{Q}_{3}$ - heat energy flow from fencing to the environment; $\mathrm{Q}_{4}$ - heat energy flow from operating area environment to fencing; $\mathrm{Q}_{5}$ - heat energy flow from operating area environment to vehicle; $\mathrm{Q}_{6}$ - heat energy flow from operating area environment to the material of the item being treated; $\mathrm{Q}_{7}$ - heat energy flow from vehicle to the material of the item being treated; $\mathrm{Q}_{8}$ - heat energy flow, released by material of the item being processed; $Q_{9}$ - heat energy flow, consumed for removing moisture from the material of item being treated; $\mathrm{q}_{1}$ - flow of moisture incoming with energy carrier; $\mathrm{q}_{2}$ - flow of moisture leaving the material of item being treated to the environment of operating area; $\mathrm{q}_{3}$ - flow of moisture leaving the heat-treatment unit with worked-out energy carrier; $E_{1}$ - store of heat energy of environment of operating area; $E_{2}$ store of heat energy of material of the item being processed; $E_{3}$ - store of heat energy of fencing; $E_{4}$ - store of heat energy of form; $M_{1}$ - store of moisture in environment of operating area; $\mathrm{M}_{2}$ - store of moisture in material of the item being processed.

On the basis of analytic model (fig. 3) and made assumptions, the following system of energy and material balance equations may be obtained:

1) energy balance of the enviroment of operating area

$$
d E_{1} / d \tau=Q_{1}-Q_{2}-Q_{4}-Q_{5}-Q_{6}-Q_{9}
$$

2) material balance of the enviroment of operating area

$$
d M_{1} / d \tau=q_{1}+q_{2}-q_{3}
$$

3) energy balance of it em material

$$
d E_{2} / d \tau=Q_{6}+Q_{7}+Q_{8}+Q_{9}
$$

4) material balance of item material

$$
d M_{2} / d \tau=-q_{2}
$$

5) energy balance of fencing material

$$
d E_{3} / d \tau=Q_{4}-Q_{3}
$$


6) material balance of fencing material

$$
d M_{3} / d \tau=0
$$

6) energy balance of vehicle

$$
d E_{4} / d \tau=Q_{5}-Q_{7}
$$

8) material balance of vehicle

$$
d M_{4} / d \tau=0
$$

Studies of authors of papers [4, 6, 7] showed that in sufficiently large range of temperature and moisture-capacity variation, heat-treatment processes have no substantially nonlinear characteristics in the time and spatial domains. Processes are practically monotonous, parameter variation is relatively small, perturbance actions have additive character.

Backed by findings of the named papers, at mathematical description of heat treatment processes for gypsum and reinforced-concrete articles, the following assumptions may be made:

- heat- and mass-exchange factors are stable at the selected control interval and within the preset range variations do not depend on temperature, moisture capacity and strength;

- temperature and moisture content of the worked-out energy carrier are equal respectively to those of the environment of unit's operating area;

- rates of energy carrier incoming to the unit and of that worked-out are equal to each other;

- transfer of heat energy from the heated vehicle to the item takes place by way of heat transfer;

- ambient temperature is permanent at control interval;

- heat exchange for the account of radiation is not available;

- intensiveness of heat emission of binding material hydration within the process of heat treatment is proportional to the temperature of item material;

- specific heat capacities of the environment of operating area, item material, vehicles and fencing within the range being considered of variation of heat-treatment process parameters are permanent.

Relying on assumptions and allowances made, the structure of heat energy and moisture flows, may be with sufficient accuracy represented by the model shown at fig. 3 .

So far as it can be supposed that elements of heat unit have lumped parameters, transfer of energy and moisture between unit elements may be characterised by the functions, which do not depend on spatial coordinates.

\section{Results}

Local flows of energy and moisture may be expressed through thermotechnical parameters.

Substitution of expressions of local energy and moisture flows to equations (8) results in a differential equation system, which may be linearized and represented in the vectormatrix form.

Having entered designations:

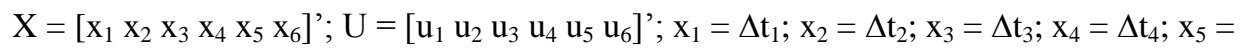

$$
\begin{aligned}
& \Delta \omega_{1} \\
& \mathrm{x}_{6}=\Delta \mathrm{u} ; \mathrm{u}_{1}=\Delta \mathrm{G}_{0} ; \mathrm{u}_{2}=\Delta \mathrm{t} ; \mathrm{u}_{3}=\Delta \omega ; \mathrm{u}_{4}=\mathrm{u}_{5}=\mathrm{u}_{6}=0 \text {, }
\end{aligned}
$$


resulting:

$$
d X / d \tau=A X+B U
$$

where: A - square matrix with dimensions 6 × 6 which characterises dynamic properties of control object; B - square matrix with dimensions $6 \times 3$ which characterises effect of control actions;

here:

$$
A=\left[\begin{array}{cccccc}
a_{11} & a_{12} & a_{13} & a_{14} & a_{15} & a_{16} \\
a_{21} & a_{22} & 0 & a_{24} & a_{25} & 0 \\
a_{31} & 0 & a_{33} & 0 & 0 & 0 \\
a_{41} & a_{42} & 0 & a_{44} & 0 & 0 \\
a_{51} & 0 & 0 & 0 & a_{55} & a_{56} \\
a_{61} & 0 & 0 & 0 & a_{65} & a_{66}
\end{array}\right] ; B=\left[\begin{array}{ccc}
b_{11} & b_{12} & 0 \\
0 & 0 & 0 \\
0 & 0 & 0 \\
0 & 0 & 0 \\
b_{51} & 0 & b_{53} \\
0 & 0 & 0
\end{array}\right],
$$

$$
\begin{aligned}
& a_{11}=-\left(F_{3 B} \alpha_{3 B}+F_{4 H} \alpha_{4 H}+F_{2 H} \alpha_{2 H} \xi_{1}+r F_{2 H} \beta_{2 H} \gamma_{0} b_{1}+\eta c_{10} G_{0}{ }^{0}\right) / c_{10} m_{10} \text {; } \\
& a_{12}=F_{2 H} \alpha_{2 H} / c_{10} m_{10} \text {; } \\
& a_{13}=F_{3 B} \alpha_{3 B} / c_{10} m_{10} ; a_{14}=F_{4 H} \alpha_{4 H} / c_{10} m_{10} ; \\
& a_{15}=-F_{2 H} \alpha_{2 H} \xi_{2} / c_{10} m_{10} \text {; } \\
& a_{16}=-r F_{2 H} \beta_{2 H} \gamma_{0} / c_{10} m_{10} \text {; } \\
& a_{2 l}=F_{2 H} \alpha_{2 H} \xi_{1} / c_{20} m_{20} \text {; } \\
& a_{22}=-\left(F_{2 H} \alpha_{2 H}+F_{2 B} K_{42}-K\right) / c_{20} m_{20} \text {; } \\
& a_{24}=F_{2 B} K_{42} / c_{20} m_{20} \text {; } \\
& a_{25}=F_{2 H} \alpha_{2 H} \xi_{2} / c_{20} m_{20} \text {; } \\
& a_{31}=F_{3 B} \alpha_{3 B} / c_{3} m_{3} \text {; } \\
& a_{33}=-\left(F_{3 B} \alpha_{3 B}+F_{3 H} \alpha_{3 H}\right) / c_{3} m_{3} ; \\
& a_{4 I}=F_{4 H} \alpha_{4 H} / c_{4} m_{4} \\
& a_{42}=F_{2 B} K_{42} / c_{4} m_{4} \text {; } \\
& a_{44}=-\left(F_{4 H} \alpha_{4 H}+F_{2 B} K_{42}\right) / c_{4} m_{4} ; \\
& a_{51}=F_{2 H} \beta_{2 H} \gamma_{0} b_{1} / m_{10} \text {; } \\
& a_{55}=-\left(F_{2 H} \beta_{2 H} \gamma_{0} b_{2}+\eta G_{0}{ }^{0}\right) / m_{10} \text {; } \\
& a_{56}=F_{2 H} \beta_{2 H} \gamma d m_{10} \text {; } \\
& a_{61}=-F_{2 H} \beta_{2 H} \gamma_{0} b_{1} / m_{20} \text {; } \\
& a_{65}=F_{2 H} \beta_{2 H} \gamma_{0} b_{2} / m_{20} \text {; } \\
& a_{66}=-F_{2 H} \beta_{2 H} \gamma_{0} / m_{20} \text {; } \\
& b_{11}=\eta c_{10}\left(t^{0}-t_{1}^{0}\right) / m_{10} \text {; } \\
& b_{12}=\eta c_{10} G_{0}{ }^{0} / m_{10} \text {; } \\
& b_{51}=\eta\left(\omega^{0}-\omega_{1}^{0}\right) / m_{10} \text {; } \\
& b_{53}=\eta G_{0}{ }^{0} / m_{10} \text {. }
\end{aligned}
$$

Process parameters: $\mathrm{t}_{3}$ - temperature of fencing, ${ }^{\circ} \mathrm{C} ; \mathrm{t}_{0}$ - ambient temperature, ${ }^{\circ} \mathrm{C} ; \mathrm{F}_{3 \mathrm{~B}}-$ surface area of fencing heat-exchange with the environment of operating area; $\alpha_{3 \mathrm{~B}}$ - heatexchange factor between fencing and the environment of operating area, $\mathrm{W} /\left(\mathrm{m}^{2} \cdot{ }^{\circ} \mathrm{C}\right) ; \mathrm{F}_{4 \mathrm{H}}-$ surface area of heat-exchange of vehicle with the environment of operating area, $\mathrm{m}^{2} ; \alpha_{4 \mathrm{H}}$ heat-exchange factor between vehicle and the environment of operating area, $\mathrm{W} /\left(\mathrm{m}^{2} \cdot{ }^{\circ} \mathrm{C}\right) ; \mathrm{t}_{4}$ - vehicle temperature, ${ }^{\circ} \mathrm{C} ; \mathrm{F}_{2 \mathrm{H}}$ - surface area of heat-exchange of item material and the environment of operating area, $\mathrm{m}^{2} ; \alpha_{2 \mathrm{H}}$ - heat-exchange factor between item material and the environment of operating area, $\mathrm{W} /\left(\mathrm{m}^{2} \cdot{ }^{\circ} \mathrm{C}\right) ; \mathrm{t}_{2}$ - temperature of item material, ${ }^{\circ} \mathrm{C} ; \xi_{0}, \xi_{1}, \xi_{2}$ - empirical factors; $\mathrm{F}_{2 \mathrm{~B}}$ - surface area of heat-exchange between item material and vehicle material, $\mathrm{m}^{2} ; \mathrm{K}_{24}$ - heat-exchange factor between item material and vehicle material, 
$\mathrm{W} /\left(\mathrm{m}^{2} \cdot{ }^{\circ} \mathrm{C}\right) ; \mathrm{K}$ - factor which includes the value and intensity of heat emissions of the binding material, amount of binding material in concrete as well as water-binder ratio, W/ ${ }^{0} \mathrm{C} ; \omega$ - moisture content of energy carrier; $\omega_{1}$ - moisture content of the environment of operating area; $\beta_{2 \mathrm{H}}$ - moisture-exchange factor, $\mathrm{m} / \mathrm{s} ; \gamma_{0}$ - specific weight of dry material of item, $\mathrm{kg} / \mathrm{m}^{3}$; u - moisture-content of material of item; $\mathrm{b}_{0}, \mathrm{~b}_{1}, \mathrm{~b}_{2}$ - empirical factors which characterise dependence between balanced moisture content of certain material and parameters of the environment of operating area; $\mathrm{m}_{10}$ - mass of the environment of operating area, $\mathrm{kg} ; \mathrm{c}_{20}$ - specific heat-capacity of item material, $\mathrm{kJ} /\left(\mathrm{kg} \cdot{ }^{\circ} \mathrm{C}\right) ; \mathrm{m}_{20}-$ active mass of item material, $\mathrm{kg} ; \mathrm{c}_{3}$ - specific heat-capacity of fencing material, $\mathrm{kJ} /\left(\mathrm{kg} \cdot{ }^{\circ} \mathrm{C}\right) ; \mathrm{m}_{3}-$ active mass of fencing material, $\mathrm{kg} ; \mathrm{c}_{4}$ - specific heat-capacity of vehicle material, $\mathrm{kJ} /(\mathrm{kg}$ $\left.{ }^{\circ} \mathrm{C}\right) ; \mathrm{m}_{4}$ - active mass of vehicle material, $\mathrm{kg} ; \mathrm{c}_{10}$ - specific heat-capacity of energy carrier and the environment of operating area, $\mathrm{kJ} /\left(\mathrm{kg} \cdot{ }^{\circ} \mathrm{C}\right)$.

The obtained mathematical model (9) generalises description of heat-treatment processes (drying-up and steam curing) being considered herein, which enables to develop universal algorithms for synthesizing control systems of those processes.

Due to the fact, that model (9) reflects distribution of energy and moisture flows between elements of heat-treatment unit, the model may be easily modified for describing heat-treatment processes in units varying in terms of design performance.

Model (9) characterises motion of control object in state space. Thermodynamical potentials which stipulate energy and substance flows which are available for immediate measurement, are accepted as state variables. In that case, outlets of the model coincide with state variables.

$$
\begin{aligned}
& d X / d \tau=A X+B U \\
& Y=I \cdot X
\end{aligned}
$$

where: Y - vector of outlets of control object model; I - identity matrix with dimension $6 \times 6$.

The empirical data obtained by the authors, allow to represent models (10) of heattreatment units being considered, as control objects within the work range in the form of a combination of linear aperiodic links of the second - third order. This evidences that researched units possess two or three most substantial capacities of heat energy and moisture.

Substantial vessels of heat energy are: steam-air medium, moulds with items and fencing of steam chamber, as shown in fig. 1.

Substantial vessels of moisture are steam-air medium (drying agent) and the items which are in the drying chamber, which part is shown in fig. 2.

In relation to the above said, transfer function of the steam chamber along channel "flow rate of heat-carrying agent - temperature of environment of operating area" has the third order and is represented as follows

$$
W_{(P)}^{S}=\frac{b_{0} p^{2}+b_{1} p+b_{2}}{a_{0} p^{3}+a_{1} p^{2}+a_{2} p+1} .
$$

In this case, transfer function of the drying chamber along channel "flow rate of drying agent - temperature of environment of operating area" has the second order and is represented as follows 


$$
W_{(P)}^{D}=\frac{b_{0} p+b_{1}}{a_{0} p^{2}+a_{1} p+1} .
$$

It should be noted that the result of the heat treatment of products can be estimated by the final strength and moisture of the products.

\section{Discussion}

To assess and predict the strength of products processed in an automated heat treatment unit, it is advisable to supplement models (12) and (13) with dependences characterizing the effect of deviations from the mode on the final strength of $R_{F}$ products. Such dependences given in $[8,9]$ were obtained on the basis of experimental studies.

For gypsum products, the dependence [8] is:

$$
R_{F}=R^{*}+K_{l} u_{0}^{*}+K_{2} d u^{*} / d \tau
$$

here: $\mathrm{R}^{*}$ - the average value of the product's strength in the same batch; $u_{0}{ }^{*}-$ the average value of the initial moisture content of products in the same batch; $d u^{*} / d \tau$ - the average value of the drying rate of the considered products batch.

In work [9], proposed the relationship, which determines the effect of the heat treatment mode violations of concrete products on their ultimate strength.

$$
R_{F}=R(T)-\sum_{i=0}^{i=k} \frac{2 \tau_{o k}}{\tau_{i o}+\tau_{i k}} \cdot \frac{\Delta R}{\Delta \tau_{i}} \cdot \tau_{g i},
$$

where: $\mathrm{R}(\mathrm{T})$ - the strength of the products obtained without disturbing the heat treatment mode; $\tau_{\mathrm{ok}}$ - the duration of the induction period of concrete hardening; $\Delta \mathrm{R} / \Delta \tau_{\mathrm{i}}$ the growth rate of strength at the $\mathrm{i}$-th moment of destruction; $\tau_{\mathrm{io}}$ - time of destruction beginning; $\tau_{\mathrm{ik}}$ - the end time of the destructive changes which occurs when the lifting or lowering speed of the treatment unit working environment temperature is exceeded; $\tau_{\mathrm{gi}}=\tau_{\mathrm{ik}}$ - $\tau_{\text {io }}$ - the duration of thermal destruction at the $\mathrm{i}$-th time point; $\mathrm{i}=1,2, \ldots, \mathrm{k}$.

Mathematical dependences (12), (13), (14), (15) adequately characterize the considered aspects of the gypsum and reinforced concrete products heat treatment process.

Experimental data obtained by many researchers gives the ability to suggest the following.

A real heat treatment process with sufficient accuracy can be represented by a simpler mathematical model than models (12) and (13). To achieve this aim, the authors of this work carried out the research on the identification of heat treatment units of gypsum and reinforced concrete products.

\section{Conclusions}

1. For the first time it is established that in general case, units for construction material thermal treatment are multi-dimensional non-stationary control objects with distributed stochastic parameters which are characterised by nonlinearities.

2. As a result, it is obtained that in the limited range of variation of processing parameters, heat-mass-exchange processes may be characterised by the linear differential equation system. 
3. Analysis of heat-mass-exchange processes in particular processing vessels allowed to develop a generalised structural model of heat-energy and moisture flows.

4. Research of heat-energy and moisture flows allowed to develop for the first time a generalised model of heat treatment of construction articles at steam curing and drying (fig. $3)$.

5. It is obtained that the order of transmission functions (12) and (13) is defined by a number of vessels of heat energy or moisture in a particular processing unit.

6. It is shown that heat-mass-exchange processes in particular processing vessels significantly affect on the strength properties of the item being processed.

\section{References}

1. V.N. Glukhov, Automatic regulation of heat-treatment and drying processes for construction articles (L.: Stroyizdat, 2014), 88 p.

2. A.A. Shevyakov, R.V. Yakovleva, Engineering methods for calculation of heatexchange unit dynamics (Moscow: Mashinostroyenie, 2017), $320 \mathrm{p}$.

3. M. Peshel, Modelling of signals and systems (Moscow: Mir, 2014), $304 \mathrm{p}$.

4. V.A. Zavyalov, S.M. Pushkaryov, N.A. Razin, Calculation of optimal control systems (Moscow: MGSU, 2014), 105 p.

5. V.A. Zavyalov, A.A. Kalmakov, S.M. Pushkaryov, Optimisation of heat-treatment process of reinforced-concrete articles by energy efficiency criterion, Izvestiya vuzov. Stroitelstvo i Arkhitektura, no. 9 (2016)

6. A.A. Kalmakov, V.A. Zavyalov, Automation of heat-treatment of reinforced-concrete articles, theses of reports of Moscow municipal conference "Technical progress and construction acceleration”, p.41 (Moscow: MGSU, 2015), 148 p.

7. L.N. Bekker, A.A. Kalmakov, V.A. Zavyalov, O.I. Ryzhkin, Multi-channel system of coordinated automated control by heat treatment of reinforced-concrete articles, Promyshlennost stroitelnykh materialov, no. 5, pp. 26-28 (2017)

8. V.A. Zavyalov, The study of the effect of drying rate on the strength properties of gypsum panels, Trudy MISI Avtomatika v stroitelstve, no. 117 (Moscow: MGSU, 2015), $200 \mathrm{p}$.

9. L.N. Bekker, The technology of heat treatment of reinforced concrete products in the conveyor mode of production, [author's abstract of dissertation to apply for the degree of the candidate of technical sciences] (Moscow: MISI, 1983), $20 \mathrm{p}$.

10. V.A. Zavyalov, V.A. Velichkin Identification of heat exchangers according to the criterion of energy efficiency Conf. ICAnCEE (2018) 